\title{
Preoperative Atrial Fibrillation and T-Wave Inversion Associated with Postoperative Pulmonary Edema
}

\author{
Thomas Hong, Benson George, Mohamad Hashim, Dennis E. Feierman \\ Department of Anesthesiology, Maimonides Medical Center, Brooklyn, NY, USA \\ Email: dfeierman@maimonidesmed.org
}

How to cite this paper: Hong, T., George, B., Hashim, M. and Feierman, D.E. (2016) Preoperative Atrial Fibrillation and T-Wave Inversion Associated with Postoperative Pulmonary Edema. Open Journal of Anesthesiology, 6, 181-185.

http://dx.doi.org/10.4236/ojanes.2016.610027

Received: August 23, 2016

Accepted: October 22, 2016

Published: October 25, 2016

Copyright $\odot 2016$ by authors and

Scientific Research Publishing Inc.

This work is licensed under the Creative

Commons Attribution International

License (CC BY 4.0).

http://creativecommons.org/licenses/by/4.0/

\begin{abstract}
Background: Atrial fibrillation (AF) and T wave inversion (TWI) are occasionally found on pre-operative electrocardiograms (EKG) of patients with long standing hypertension (HTN) associated with left ventricular hypertrophy (LVH). Each of these two pathologies, AF and LVH, can impose negative hemodynamic effects on the cardiac function. Case: We present a case of a patient with AF, TWI and long standing HTN that went into post-operative pulmonary edema. Conclusion: Even returning to base line poorly controlled hypertension, and even more so during a hypertensive crisis, their concurrent presence may inflict even more detrimental effect manifested by elevation of pulmonary venous pressure and pulmonary edema.
\end{abstract}

\section{Keywords}

Pulmonary Edema, Atrial Fibrillation, T Wave Inversion

\section{(c) (i) Open Access}

\section{Introduction}

One of the most common serious cardiac dysrhythmias is atrial fibrillation. A condition that shares many risk factors as atrial fibrillation is diastolic dysfunction. Diastolic dysfunction can arise from chronic hypertension that had led to left ventricular hypertrophy. Diastolic dysfunction in itself has an impact on atrial structure and function, which may be pro-arrhythmic [1]. Preoperative hypertension is usually attributed to anxiety. It is known that hypertensive crisis can lead to extreme cardiac impairment [2]. This combined with AF and LVH with diastolic dysfunction may pose significant perioperative risk for complications. We present a case where a patient developed postoperative flash pulmonary edema as a result of unrecognized significant diastolic dysfunction and uncontrolled hypertension. The only preoperative findings in this case 
were lateral T-wave inversion accompanied with atrial fibrillation on EKG.

\section{Case Report}

A 74-year-old male presented to ambulatory surgical center for cystourethroscopy and lithotripsy. The patient had a history of hypertension, atrial fibrillation (AF), and non-insulin dependent diabetes mellitus. Preoperatively, patient vital signs were (HR 77, BP 147/98, RR 18, and Temp 98.4) and the physical exam was within normal limits. EKG showed rate-controlled AF with TWI in the lateral leads (Figure 1). Induction was performed with fentanyl, propofol and etomidate. A supraglottic airway was placed and anesthesia was maintained with sevoflurane. The surgery lasted 90 minutes and intraoperative course was uneventful. Intraoperative fluid administration was $200 \mathrm{ml}$ of Lactated Ringers' solution.

Two hours postoperatively, patient blood pressure progressively increased to his base line (poorly controlled) hypertension. There was a gradual decrease in oxygen saturation, reaching a nadir of $88 \%$, associated with bilateral rales and moderate dyspnea. This was additionally associated with an increase in blood pressure to 270/150, heart rate of 120. Patient was placed on facemask oxygen, and aggressively treated with furosemide and labetalol. An ABG, EKG, CXR was also obtained. ABG was PH 7.19/ $/ \mathrm{PCO}_{2}$ 59/PO2 57, lactate 5.6. After treatment, EKG showed rate controlled AF with TWI, unchanged from the preoperative EKG. Chest X-ray (Figure 2) and CT scan were consistent with bilateral pulmonary edema. Patient was then transferred to the hospital where he was managed in their PACU. The patient was intubated due to worsening of respiratory symptoms. After intubation, pink-tinged secretions were appreciated in the ET tube, consistent with pulmonary edema. Diagnostic tests were performed: cardiac en-

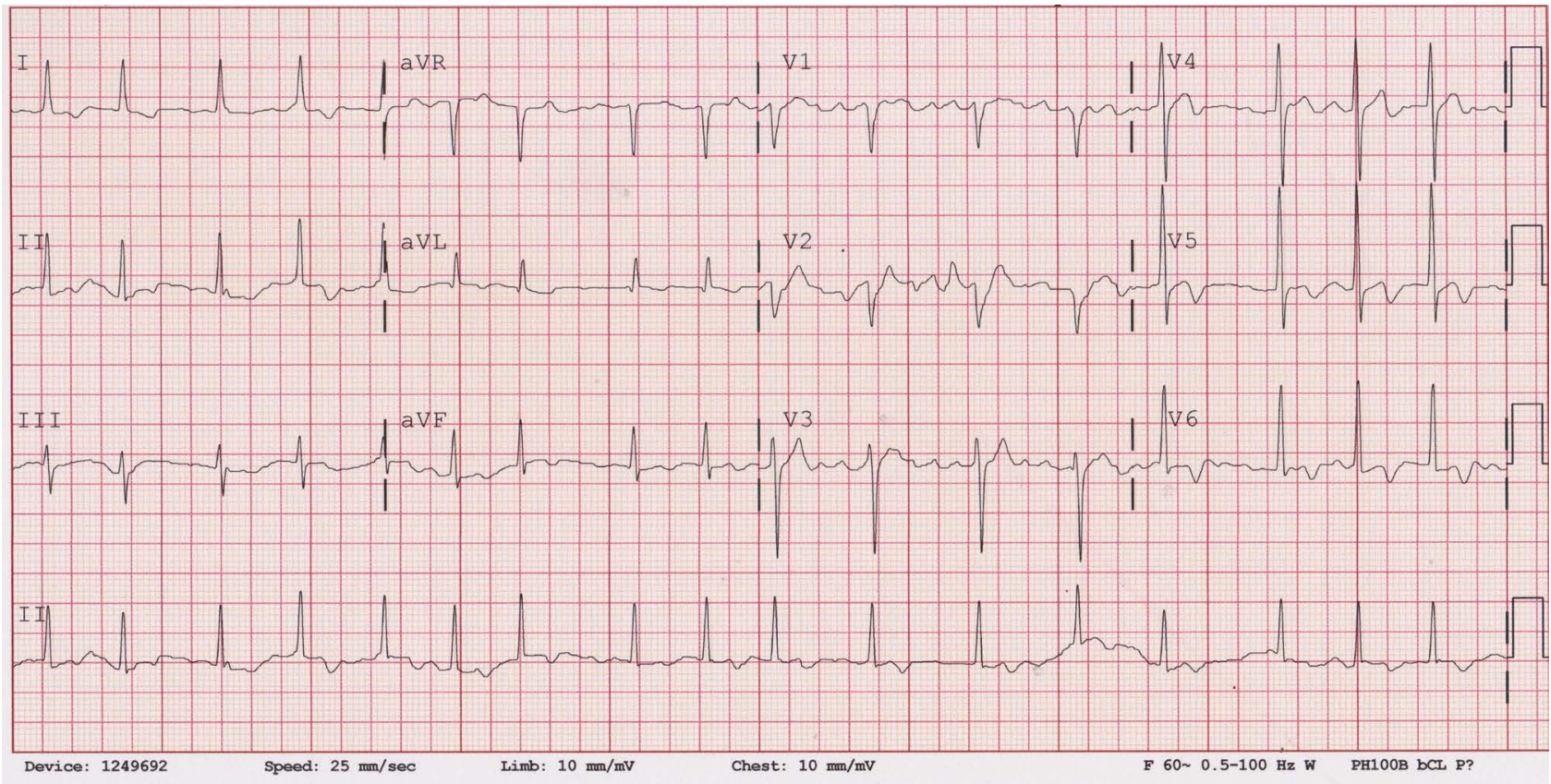

Figure 1. Preoperative EKG showing atrial fibrillation and lateral lead T-wave inversions. 


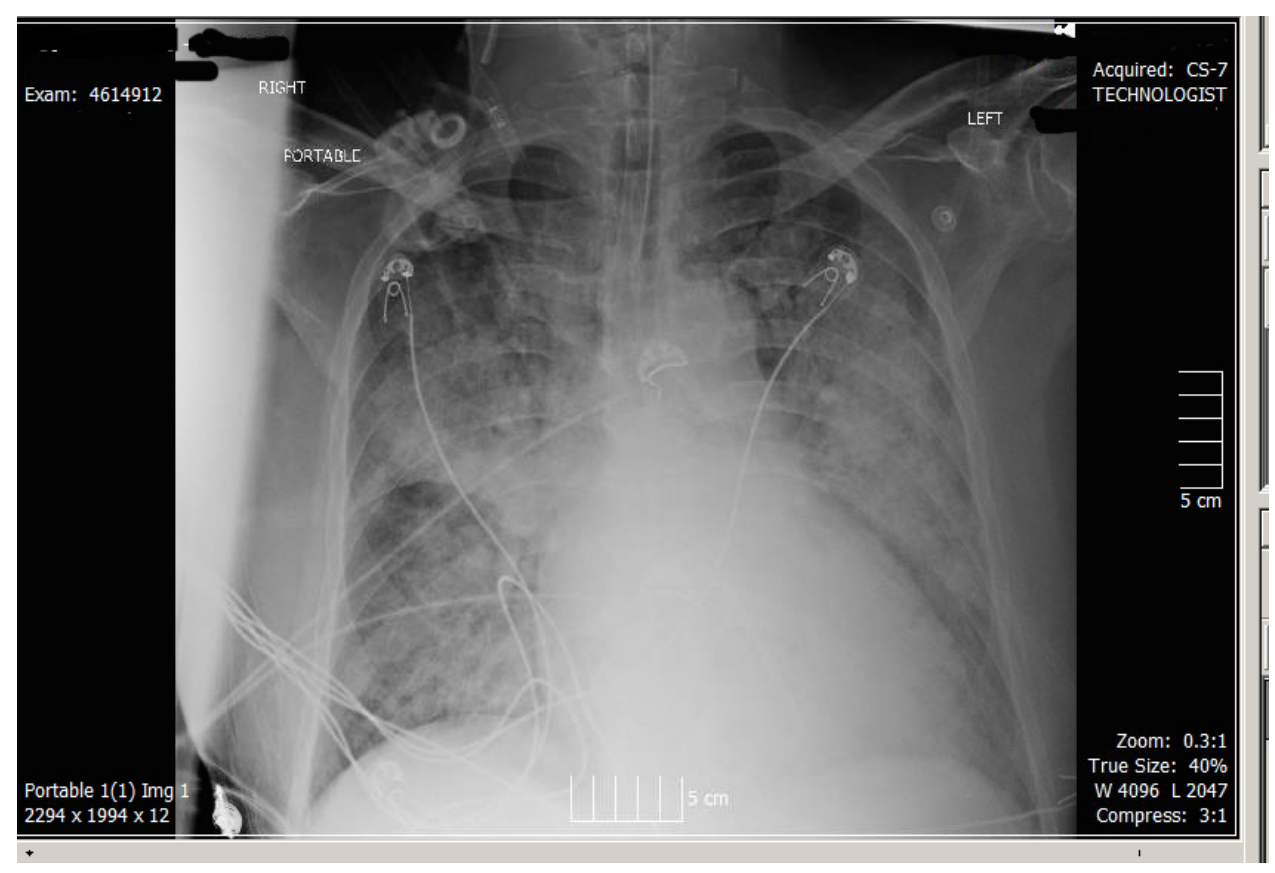

Figure 2. Postoperative Chest X-ray showing bilateral pulmonary edema.

zymes and Brain Natriuretic Peptide were normal, echocardiogram showed EF 65\%, bicuspid aortic valve, and minimal pericardial effusion. Patient responded well to diuretics and metoprolol and was successfully extubated the next day and discharged home on post- operative day five.

\section{Discussion}

Atrial fibrillation is the most common serious cardiac arrhythmia. Its prevalence starts at $0.5 \%$ in people ages $50-59$, and doubles every decade of life to almost $9 \%$ in people 80 - 89 [3]. Atrial fibrillation affects all four stages of ventricular filling. These include isovolumetric relaxation, early rapid filling, diastasis, and atrial systole. Diastolic dysfunction is a condition that shares many risk factors with atrial fibrillation, and prevalence also increases with age [4]. LVH with a strain pattern on EKG is likely to be associated with a thick ventricle and likely to have diastolic dysfunction. Diastolic dysfunction in itself has an impact on atrial structure and function, which may be arrhythmogenic [1]. Diastolic dysfunction encompasses three basic problems: 1) impaired ventricular lusitropy; 2) decreased ventricular compliance; and 3) increased atrial filling pressure. The degree of diastolic dysfunction is best assessed with echocardiogram. One methodology used to determine degree of diastolic dysfunction is the ratio of E/A waves, which is the ratio of early mitral inflow velocity to late ventricular filling velocity [5]. However, since the A wave is dependent on atrial kick, this method is unreliable in atrial fibrillation. Therefore in patients with atrial fibrillation the ratio of E/e' is used, which is the ratio of early mitral inflow to early diastolic annular motion [5]. Superiority of E/A versus $\mathrm{E} / \mathrm{e}$ ' is unclear in the literature.

The presence of coexisting atrial fibrillation and diastolic dysfunction from LVH in 
the setting of poorly controlled hypertension can lead to flash pulmonary edema requiring tracheal intubation. This was a diagnosis of exclusion as the other causes of pulmonary edema were ruled out. Intraoperative fluid administration was limited to $200 \mathrm{mls}$ and cardiogenic pulmonary edema was ruled out during the hospital course. Allergic reaction was ruled out due to the absence of hypotension, bronchospasm, and a cutaneous rash. In this patient the only evidence of diastolic dysfunction was the presence of T-wave inversions on EKG, which by itself is non-specific for diastolic dysfunction. However, it has been shown in limited studies that $\mathrm{T}$-wave inversion is associated with increased odds of diastolic dysfunction in patients with preserved ejection fraction [6].

This patient's baseline blood pressure was poorly controlled (BP 147/98). The patient started to have problems (decreased saturations) when his blood pressure approached his preoperative baseline that was also exacerbated by an increase in the heart rate. One of the postoperative goals is to have the BP within $\pm 20 \%$ of baseline prior to discharge. In cases where the patient may have significant diastolic dysfunction, higher blood pressures may increase demand in a hypertrophic ventricle that already has increased demand, which can possibly lead to increased diastolic dysfunction. Therefore, it may be prudent to ensure that the patient's blood pressure is kept lower than his preoperative blood pressure by $10 \%-20 \%$.

In this case, we saw a patient with poorly controlled hypertension who presented for ambulatory surgery that developed flash pulmonary edema during the post-operative course. Preoperatively, the only evidence of cardiac abnormalities was an EKG with controlled AF and $\mathrm{T}$-wave inversion in the lateral leads. The T-wave inversion suggests that this patient had diastolic dysfunction. Many times, preoperative elevations in BP are usually minimized and are considered secondary to anxiety. Therefore, our postoperative goal should have been to maintain his blood pressure below his preoperative value. We believe that the increase in blood pressure lead to a worsening in diastolic dysfunction, and that coupled with AF lead to pulmonary congestion, which lead to decrease saturations, which in turn lead to a sympathetic response. These events caused an additional increase in blood pressure and heart rate and that caused further diastolic dysfunction and flash pulmonary edema. Severe hypertensive crisis have been known to cause pulmonary edema [2]. Secondary causes of pulmonary edema such as acute myocardial infarction and fluid overload were ruled out, and therefore we conclude that the constellation of atrial fibrillation, diastolic dysfunction, and hypertensive episode led to pulmonary edema.

\section{Conclusion}

In patients who present to ambulatory centers, often a full medical workup has not been done or may not be available. Therefore, we recommend that patients with atrial fibrillation and hypertension associated with T-wave inversions on EKG should have: 1) strict perioperative blood pressure and heart rate control; 2) limited administration of fluids; and 3) adequate pain management in the recovery room to limit any hypertensive episodes. Although the ACC guidelines would not recommend further cardiac evaluation, since the T-wave inversion with LVH has significant odds of diastolic dysfunction, it might be warranted to have an echocardiogram in patient with long stand- 
ing poorly controlled HTN and LVH, to gauge the extent of their diastolic dysfunction to alert the anesthesiologist of the importance of tight perioperative control of blood pressure and heart rate in these patients.

\section{References}

[1] Rosenberg, M.A. and Manning, W.J. (2012) Diastolic Dysfunction and Risk of Atrial Fibrillation: A Mechanistic Appraisal. Circulation, 126, 2353-2362. http://dx.doi.org/10.1161/CIRCULATIONAHA.112.113233

[2] Kanaan, N., Persu, A., Van Ingelgem, G., Malaise, J. and Goffin, E. (2008) Recurrent Pulmonary Oedema and Severe Hypertension after Renal Transplantation: Other Reasons than Renal Artery Stenosis. Nephrology, Dialysis, Transplantation, 23, 397-399. http://dx.doi/10.1093/ndt/gfm628

[3] Kannel, W.B., Wolf, P.A., Benjamin, E.J. and Levy, D. (1998) Prevalence, Incidence, Prognosis, and Predisposing Conditions for Atrial Fibrillation: Population-Based Estimates. American Journal of Cardiology, 82, 2N-9N. http://dx.doi.org/10.1016/S0002-9149(98)00583-9

[4] Zile, M.R. and Brutsaert, D.L. (2002) New Concepts in Diastolic Dysfunction and Diastolic Heart Failure: Part I: Diagnosis, Prognosis, and Measurements of Diastolic Function. Circulation, 105, 1387-1393. http://dx.doi.org/10.1161/hc1102.105289

[5] Sohn, D.W., Chai, I.H., Lee, D.J., Kim, H.C., Kim, H.S., Oh, B.H., Lee, M.M., Park, Y.B., Choi, Y.S., Seo, J.D. and Lee, Y.W. (1997) Assessment of Mitral Annulus Velocity by Doppler Tissue Imaging in the Evaluation of Left Ventricular Diastolic Function. Journal of the American College of Cardiology, 30, 474-480.

http://dx.doi.org/10.1016/S0735-1097(97)88335-0

[6] Ofman, P., Cook, J.R., Navaravong, L., Levine, R.A., Peralta, A., Gaziano, J.M., Djousse, L., Curillova, Z., Hoffmeister, P., Smoot, K., Jiang, L., Tighe, D.A. and Stoenescu, M.L. (2012) T-Wave Inversion and Diastolic Dysfunction in Patients with Electrocardiographic Left Ventricular Hypertrophy. Journal of Electrocardiology, 45, 764-769. http://dx.doi/10.1016/j.jelectrocard.2012.06.001

Submit or recommend next manuscript to SCIRP and we will provide best service for you:

Accepting pre-submission inquiries through Email, Facebook, LinkedIn, Twitter, etc. A wide selection of journals (inclusive of 9 subjects, more than 200 journals)

Providing 24-hour high-quality service

User-friendly online submission system

Fair and swift peer-review system

Efficient typesetting and proofreading procedure

Display of the result of downloads and visits, as well as the number of cited articles Maximum dissemination of your research work

Submit your manuscript at: http://papersubmission.scirp.org/

Or contact ojanes@scirp.org 